\title{
LOS YACIMIENTOS CON ENTERRAMIENTO EN SILO. UNA APROXI- MACIÓN AL CONOCIMIENTO DE LAS PRÁCTICAS FUNERARIAS DU- RANTE LA PREHISTORIA RECIENTE EN LA CAMPIÑA LITORAL Y BANDA ATLÁNTICA DE CÁDIZ. ESTADO DE LA CUESTIÓN.
}

Adolfo Moreno Márquez ${ }^{1}$

\begin{abstract}
Resumen
El estudio de los enterramientos neolíticos, muestra una serie de problemas de muy diversa consideración, como son cronologías, tipología, ideología, etc. Entre las diferentes estructura de enterramiento, las inhumaciones en silo son las que generan una mayor problemática. Con el presente trabajo se pretende llevar a cabo un estado actual de la cuestión en el extremo sur de la Península Ibérica (Bahía de Cádiz). Se presenta los yacimientos con enterramiento en silo de esta zona, donde los estudios de los restos óseos han sido los grandes olvidados.

Palabras clave

Bahía de Cádiz, neolítico, bioarqueología, practicas funerarias, desigualdad social.

Abstract

The study of neolithic interments, shows a series of problems very diverse consideration, such as chronologies, typology, ideology, etc. Among the different structure burial burials in silo they are generating more problematic. With the present work it is to carry out a current state of affairs in the south of the Iberian Peninsula (Bay of Cadiz). With burial deposits is presented in silo this area, where studies of skeletal remains have been the forgotten .
\end{abstract}

\section{Key words}

Bay of Cadiz, Neolithic, bioarcheology, burial practices, social inequalities.

\section{Introducción}

El estudio antropológico de los restos óseos procedentes de estructuras funerarias localizadas en la Campiña Litoral y Banda Atlántica de Cádiz, es el eje central de la tesis doctoral que actualmente me encuentro desarrollando. Por tanto y como indica el título, este trabajo muestra los yacimientos con enterramiento en silo que se localizan en esta zona, con el fin de mostrar diferencias y simili-

1 Investigador Grupo PAI-HUM 440. Predoctoral Universidad de Cádiz.

adolfomorenomarquez@gmail.com

Revista Otarq - ISSN 2530-4933

Vol. 1 2016, pp. 85-101 
tudes entre ellos y que servirán de base para posteriormente realizar el estudio antropológico de sus restos óseos humanos. Durante las últimas décadas, se han localizado una serie de yacimientos arqueológicos de época prehistórica con enterramientos, que vienen a aportar nuevos datos para la comprensión global del mundo funerario. Desde un punto de vista, se estudian las tipologías de las estructuras de enterramientos: dólmenes, fosos, silos, cuevas naturales, cuevas artificiales o cista; así como el estudio del contenido de la propia estructura: inhumación individual o colectiva, primaria o secundaria, el tipo de ajuar que presenta, etc. A ello se pretende aportar mediante la investigación que se está llevando a cabo, el estudio antropológico de los restos óseos, el cual en décadas anteriores los huesos eran "uno de los olvidados" ya que pasaban a un segundo plano a diferencia de la cerámica, la industria lítica u otros objetos. El análisis en conjunto de todos estos puntos, aporta una gran información y ayuda a comprender los posibles cambios internos en las sociedades prehistóricas y aparte, muestra las desigualdades sociales que transciende más allá de la muerte (Moreno, 2015:113).

\section{Los registros funerarios en silo en la Campiña litoral y Banda Atlántico de Cádiz. Estado de la Cuestión.}

Entre mediados y finales del $\mathrm{V}^{\circ}$ milenio y segunda mitad del $\mathrm{IV}^{\circ}$ milenio a.n.e. los grupos poblacionales comienzan a establecerse de manera permanentes en zonas concretas con el fin de controlar el territorio y los diferentes bienes de consumo (Ramos y Cantalejo, 2015). Esto favoreció progresivamente el aumento y control de la explotación agrícola y a su vez al reparto de estos bienes generados, propiciando una serie de contradicciones sociales y siendo el germen de las primeras desigualdades sociales (Nocete, 2001). Con el fin de almacenar estos bienes, se construyen unas estructuras en el subsuelo a modo de contenedor, a las que se le ha denominado silos. En algunos casos, cuando estas estructuras pierden su función inicial de almacenaje, son reutilizadas como estructuras de enterramientos, donde se localizan inhumados una gran parte del grupo poblacional. Es muy significativo que dichos enterramientos no suele aparecer con un ritual claro, como ocurriría en otro tipo de estructuras que son construidas para un único fin, como son los dólmenes, las cuevas o las fosas. Esto se justifica debido a que en muchas ocasiones los restos humanos aparecen revueltos con otros materiales como son cerámica, industria lítica o fauna, pero sin ningún tipo de ajuar característico. La presencia de fauna en los enterramientos, generan diversas hipótesis, sobre todo en los restos que aparecen con marcas de corte y/o desarticulados, siendo una clara muestra de consumo de carne animal por parte de estas poblaciones (Nocete, 2001); mientras que los restos de animales que aparecen completos o sin marcas de consumo, son más entendidos como el resultado de rituales relacionados por estos grupos. Por la contextualización de ciertas estructuras, tienen una clara función de fundación 
y vinculación al terreno apropiado, no solo como lugar de explotación agrícola, sino también como una afirmación de la propia posición en los inicios de la jerarquización (Cámara, 2001; Lizcano y Cámara, 2004; Cámara et al., 2010: 315).

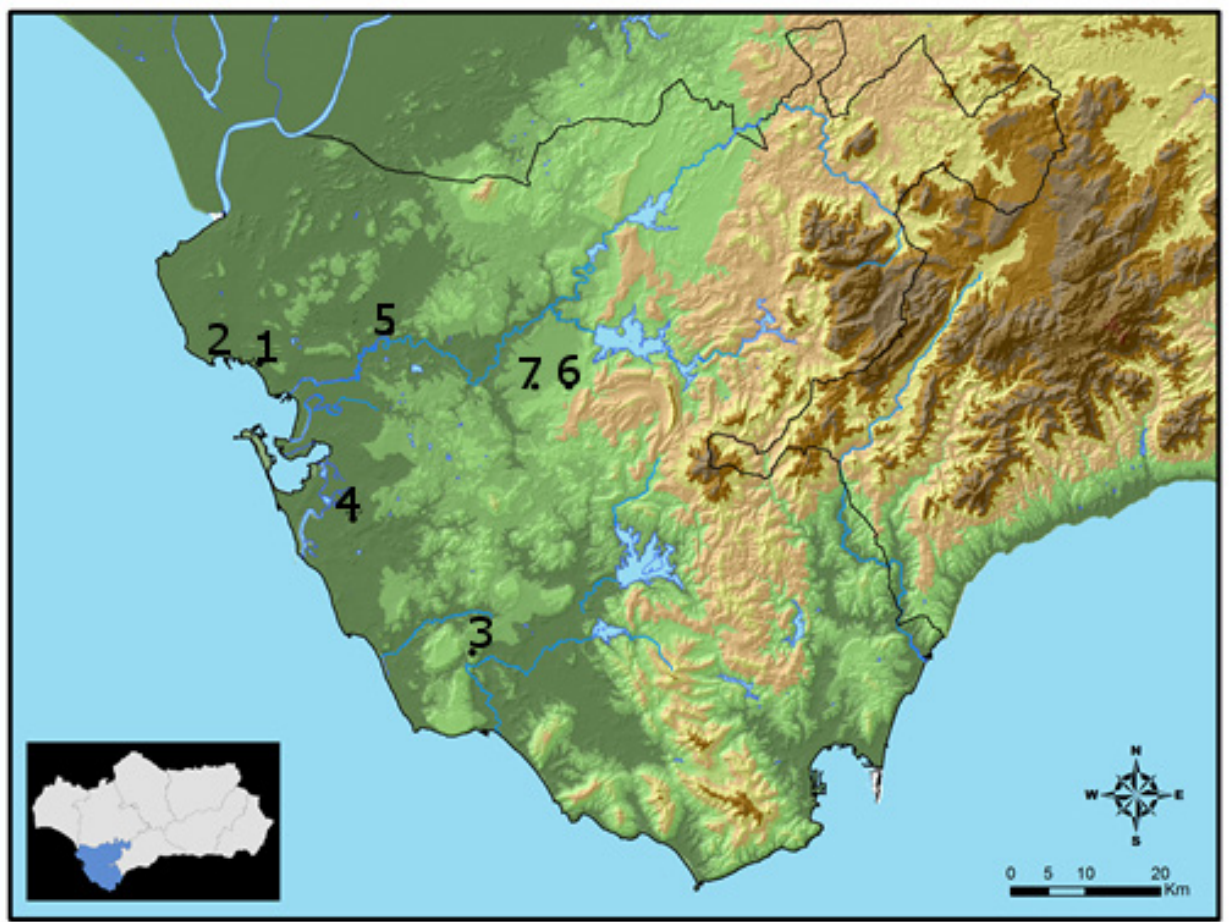

Figura 1. Mapa de la distribución de los yacimientos con enterramientos en silo.

En conclusión, es posible que en ocasiones, no se trate de enterramientos intencionados; mientras que en otras sí se observa claramente una intencionalidad y por ello se entiende como una manifestación funeraria con un cuidado ritual. Esta problemática se deriva claramente en la intencionalidad de los enterramientos en estas estructuras (Márquez y Jiménez, 2010:233). En la Campiña Litoral y Banda Atlántica de Cádiz (figura 1) los yacimientos con enterramientos en silo que se conocen son: Las Viñas-Cantarranas (Figura 1:1) (Puerto de Santa María) (Ruiz y Ruiz, 1986), Base Naval de Rota (Figura 1:2) (Puerto de Santa María) (Ruíz y Ruíz, 1987), SET Parralejos (Figura 1:3) (Vejer de la Frontera) (Villalpando y Montañés, 2009), La Esparragosa (Figura 1:4) (Chiclana de la Frontera) (Pérez et al.,2005), El Trobal (Figura 1:5) (Jerez de la Frontera) (González, 1986), El Jadramil (Figura 1:6) (Arcos de la Frontera) (Lazarich, 2003) y Necrópolis las Valderas (Figura 1:7) (Arcos de la Frontera) (Corzo, 1983). Por tanto no se pueden considerar como algo poco presente en la zona (Moreno, 2015:115). 


\title{
Yacimientos con enterramientos en silo en la Campiña y Litoral Banda Atlántica de Cádiz
}

\author{
Las Viñas-Cantarranas (El Puerto de Santa María, Cádiz)
}

\section{Ubicación}

Ambos yacimientos se localizan en el término municipal de El Puerto de Santa María y forman parte de un conjunto de yacimientos muy próximos entre sí de cronología prehistórica.

\section{Historia de la investigación}

Este conjunto de yacimientos fueron excavados a lo largo de los años 80 y se dividen en 3 áreas: una zona de taller donde se han documentado un considerable número de piezas líticas con un claro predominio de la industria microlíti$\mathrm{ca}$, junto con la presencia de hachas, molinos barquiformes, piedras de moler y machacadores circulares, (siendo claras evidencias de la funcionalidad agrícola); otra área de fondos de cabañas y una tercera área correspondiente a las estructuras siliformes (silos). Respecto a la cerámica, se localizan algunos fragmentos decorados (incisa y pintada) (Ruíz, 1986:98). Este poblado sufre una ocupación intensa durante el tránsito de los períodos Neolítico-Calcolítico (Ruíz, 1986:98).

Las propuestas de sus investigadores, es que la zona excavada y estudiada es parte de un amplio complejo fundamentalmente calcolítico que se sitúa a lo largo de la línea de costa y en torno posiblemente al arroyo Salado, con el fin de obtener recursos agrícolas a la vez de una fuerte dependencia del mar como fuente de recursos y base alimenticia. Los restos alimenticios, lo constituyen principalmente moluscos en general junto con restos óseos de cápridos y bóvidos (Ruíz, 1986:99).

\section{Enterramiento}

Uno de estos silos estaba ocupado por un enterramiento colectivo en posición fetal y con ajuar cerámico. A pesar de contener una inhumación completa, aparecieron fragmentos de cráneo correspondientes a otros dos individuos (Ruiz, 1986).

\section{Base Naval de Rota (El Puerto de Santa María, Cádiz)}

\section{Ubicación}

Este yacimiento está situado en terrenos de la Base Naval de Rota, pero en el término municipal del Puerto de Santa María, muy próximo a los yacimientos de 
"Las Viñas- Cantarranas". Su cercanía al mar, le convierte en un punto muy estratégico (Ruiz y Ruiz, 1989).

\section{Historia de la investigación}

Fue excavado durante el mes de julio de 1986 a causa de unas obras de construcción de viviendas militares próximas a la zona de la Base Naval de Rota. Debido al desmonte del cerro se localizaron diversas ocupaciones: una necrópolis romana con 15 tumbas; y doce silos de época prehistórica. Los silos estaban agrupados en pequeños conjuntos de tres o cuatro (Ruiz y Ruíz, 1989).

\section{Estructuras funerarias y ajuar.}

Se localizó un silo con un enterramiento en posición fetal, junto con varios huesos largos no correspondientes a ese primer individuo (figura 2). El ajuar se caracterizaba por la presencia de industria lítica (microlámina) y cerámica (platos de bordes almendrados) las cuales tienen las mismas tipologías que las aportadas con otro yacimiento del mismo horizonte cultural y cercano, como es Cantarranas. Esta similitud, también se observa en las propias estructuras de silos (Ruiz y Ruiz, 1989:9).

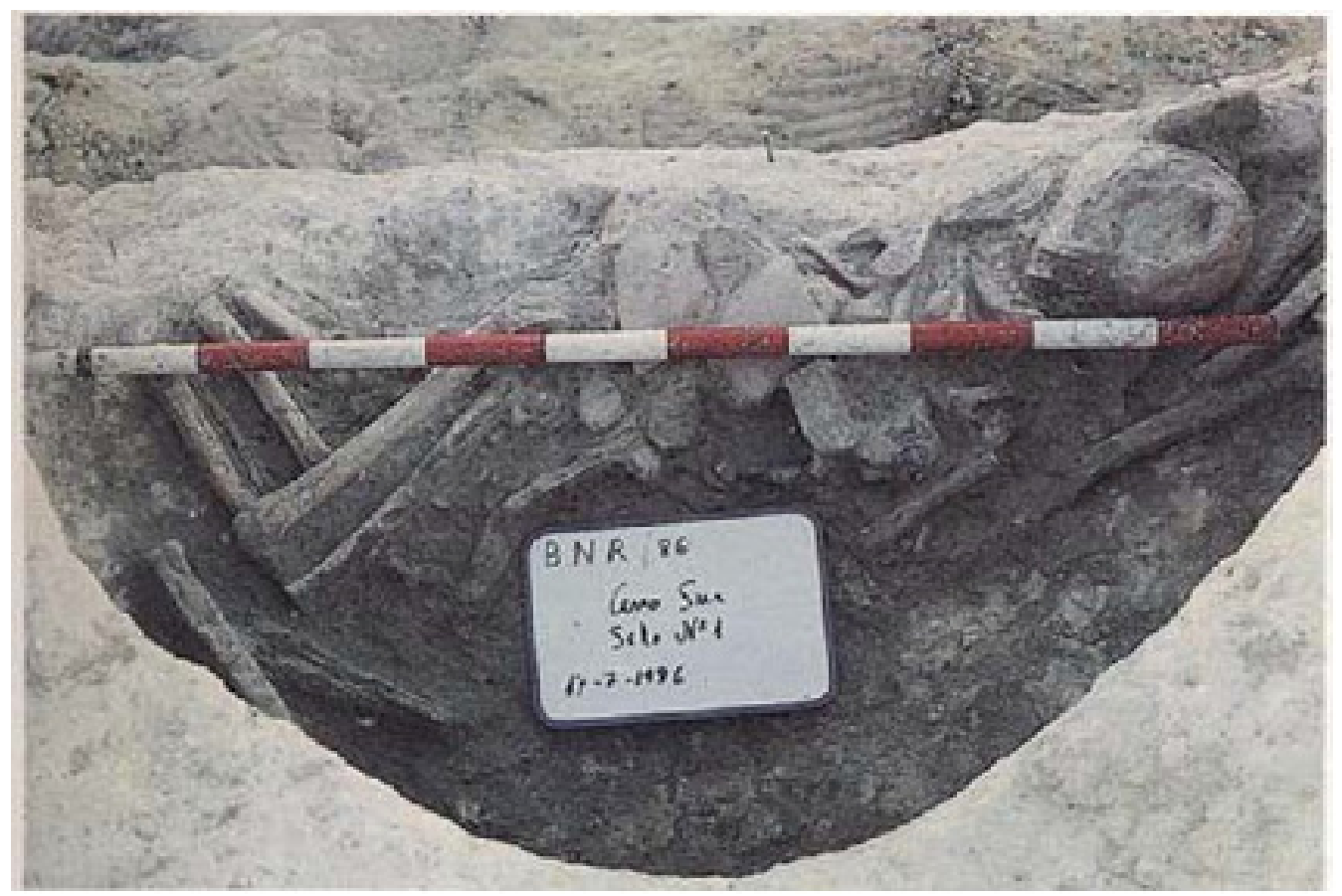

Figura 2. Sección del silo con inhumación (Ruiz y Ruiz, 1989: 9). 


\section{La Esparragosa (Chiclana de la Frontera, Cádiz)}

\section{Ubicación}

Se encuentra a escasos kilómetros del casco urbano de Chiclana de la Frontera. Es un asentamiento al aire libre situado en el extremo oriental de la Bahía de Cádiz, en plena campiña litoral. Se localizaría en una plataforma sobre el río Iro, formado por un conjunto de arenas amarillas de época del Plioceno (Pérez et al., 2005).

\section{Historia de la investigación}

Se realizó una campaña de excavación en 2002, donde se excavaron 9 estructuras siliformes, destacando sus secciones acampanadas y cilíndricas y localizando un material arqueológico propio de finales del IV ${ }^{\circ}$ milenio a.C. La cerámica está compuesta por cuencos variados, ollas, fuentes carenadas, etc. Entre la industria lítica destacan lascas internas, levallois y hojas, junto con varios fragmentos de piedras de molinos y moletas así como de pulimentos; hay que destacar la presencia de restos de lustre de cereal en varias hojas con retoques de uso, lo que confirma una importante actividad agrícola. Se realizaron varios análisis de funcionalidad sobre las hojas de láminas, mostrando rastros de uso similar a actividades como el escamado y fileteado, posiblemente usadas como "cuchillos para pescado" (Pérez et al., 2005). En el año 2004 se realizó una nueva intervención arqueológica donde se excavaron 108 estructuras (silos, fosos y basureros) correspondiendo la mayor parte de ellos a época Calcolítica, aunque 17 de ellas contenían material de época Neolítico Final (Pérez et al., 2005).

La Esparragosa es un poblado sedentario con una importante actividad agrícola y ganadera que se ve complementada por su proximidad al mar con diferentes tareas marítimas. Su adscripción, a finales del IV milenio B.C. (datación BP: 5255 \pm 433 - Laboratorio: MAD-3961), se da en base a dos dataciones de Termoluminiscencia efectuadas sobre muestras cerámicas (Ramos (coord.), 2008: 344).

\section{Estructuras funerarias y ajuar.}

En la campaña de 2002, se localizó un enterramiento en una estructura con un diámetro mayor que el de los silos. En él se documentó un individuo en conexión anatómica y en posición encogida. Lo más significativo es que estaba el individuo completamente cubierto por 477 Ruditapes decussatus (almejas) (muchas de ellas aún cerradas) (figura 3) (Vijande, 2006). 


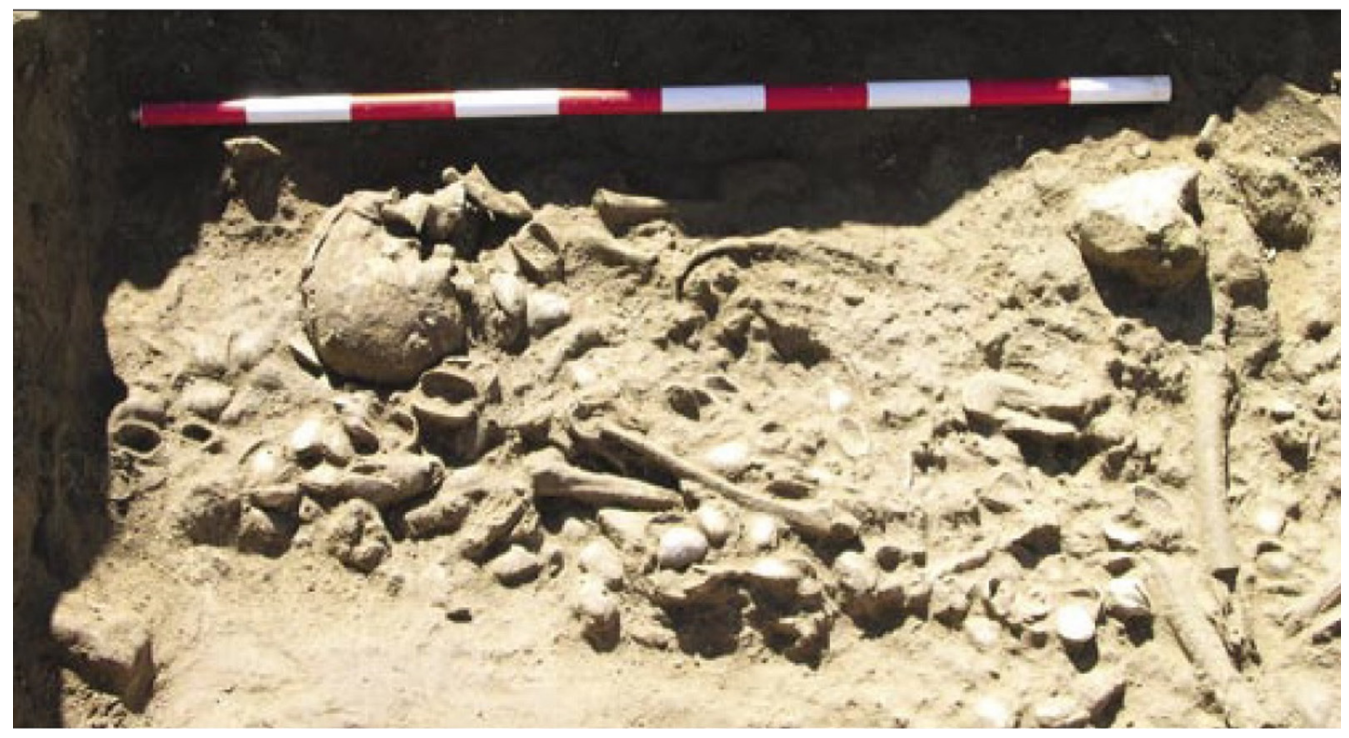

Figura 3. Detalle enterramiento (Vijande, 2006).

\section{SET Parralejos(Vejer de la Frontera, Cádiz)}

\section{Ubicación}

El yacimiento se localiza en un cerro próximo a la localidad de Vejer de la Frontera (Cádiz), en la antigua zona de la laguna de La Janda. Desde él se controla los espacios naturales delimitados por las cuencas de los ríos Barbate y Salado, así como la franja litoral (Villalpando y Montañés, 2009).

\section{Historia de la investigación}

El hallazgo del sitio arqueológico se produjo en el año 2008, durante los trabajos de control de movimiento de tierras de la subestación eléctrica Parralejos. Durante los trabajos arqueológicos se excavaron 33 silos de un total de los 58 localizados, con una tipología de sección cilíndrica, acampanada, pozos y "falsos silos o cubetas" (Villalpando y Montañés, 2009). Entre los materiales cerámicos encontrados se constatan cuencos (variados, de casquete esférico, semiesférico y escudillas), ollas (de paredes entrantes y de perfiles oblongos y globulares) y fuentes carenadas (propias de contextos del IV ${ }^{\circ}$ milenio a.C.). Mientras que la industria lítica tallada se caracteriza por su tipología laminar: perforadores, escotaduras, denticulados, láminas de dorso, buriles, foliáceos de punta de aleta y pedúnculo. También hay presencia de hachas, azuelas, moletas y molinos de mano (Villalpando y Montañés, 2009; Cuenca et al., 2013). 
Por su proximidad al mar, se ha localizado el consumo de la misma, mostrando un predominio de especies bivalvas, destacando Ruditapes decussatus. Entre este material hay al menos un ejemplar de Zonaria pyrum, en el que se observa una manipulación antrópica para ser usado como adorno (Cuenca et al, 2013).

Se realizaron diversas dataciones de C-14, que oscilan entre 3522 y 3014 cal. a.C. (Laboratorio: CNA-649) (Villalpando y Montañés 2009).

\section{Estructuras funerarias y ajuar}

En relación a las prácticas funerarias cabe señalar la documentación de 11 individuos enterrados en cierto modo de manera secundaria (existen evidencias de algunos miembros en posición anatómica) repartidos entre 4 estructuras de silo, en sucesivas unidades estratigráficas. El silo más significativo es el 106, donde se documentaron cinco individuos en sucesivas unidades estratigráficas (figura 4). No se documentó ningún elemento de ajuar (Villalpando y Montañés, 2009).

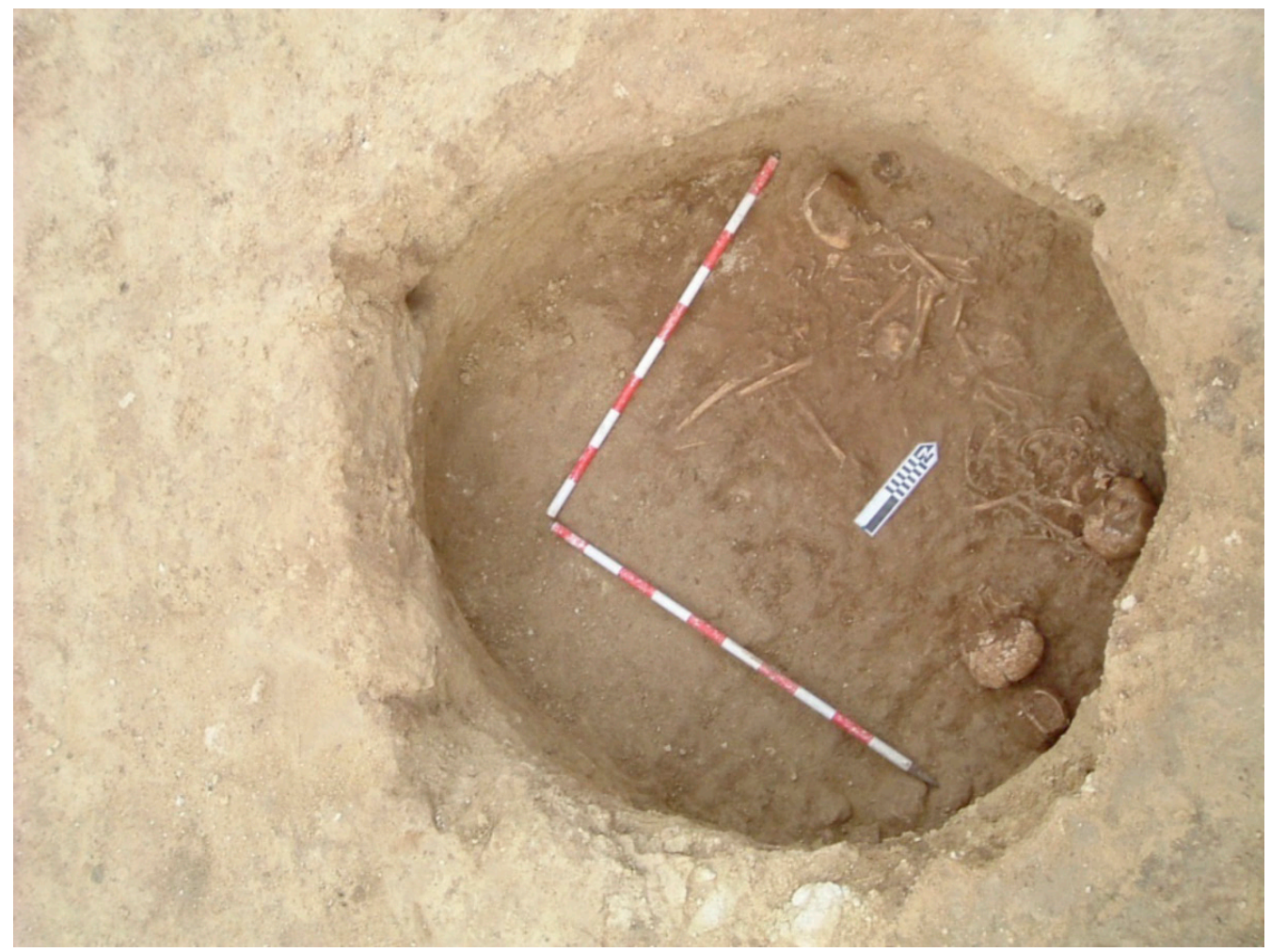

Figura 4. Detalle enterramiento (Villalpando y Montañés, 2009). 


\section{El Trobal (Jerez de la Frontera, Cádiz)}

\section{Ubicación}

El yacimiento se encuentra muy cercano a la población de Nueva Jarilla y a unos $13 \mathrm{~km}$. al Nordeste de la localidad de Jerez de la Frontera, en la cercanía de la antigua Ilanura diluvial de Caulina (González, 1986:80).

\section{Historia de la investigación}

En 1984, debido a la actividad industrial de una cantera cercana, se dejó al descubierto una estructura de tipo siliforme y donde se conservaba parte de un cráneo, un cuchillo de cobre, algunos punzones de hueso y materiales cerámicos y líticos. Este material permitió encuadrarlo cronológicamente en un horizonte de Calcolítico Pleno. Debido a la apertura de nuevas zonas de trabajo en la cantera, se obligó a la realización de la campaña de excavación con el fin de salvar el yacimiento entre 1985 y 1986, donde se localizaron y excavaron 40 estructuras siliformes con una cierta concentración por núcleos. Predominan los de perfil acampanado y planta circular, aunque es difícil fijar la profundidad, ya que, muchas estructuras habían sido afectadas por la maquinaria en la parte superior. El contenido de los rellenos muestran es variado: tierra, pequeños carboncillos, restos de adobes y aglomeraciones de piedras (González, 1986:82).

La cerámica es a mano y alisada, aunque algunas aparecen bruñidas: cazuelas carenadas, vasos de cuerpo esférico y paredes verticales, ollas globulares y platos. En cuanto a la industria lítica, en su mayoría, está realizada en sílex (las lascas de talla, las hojas y láminas de sección triangular y trapezoidal) también aparecen perforadores sobre lámina, raspadores, algún buril y tan sólo dos puntas de flecha (una de base cóncava y otra con un cierto desarrollo de las aletas). También aparecen fragmentos de hachas, molinos y manos de moler, machacadores, bruñidores o alisadores, etc. (González, 1986:86).

\section{Estructuras funerarias y ajuar}

De las cuarenta estructuras excavadas, solo cuatro contenían restos óseos humanos con diferentes disposiciones internas. Tanto la estructura Z-1(1,70 m. de diámetro de base, $1 \mathrm{~m}$. de profundidad y aproximadamente $0,50 \mathrm{~m}$. de anchura de boca), como la estructura B, (con $3 \mathrm{~m}$. de ancho por 1,50 m. de altura) comparten la similitud de que los restos óseos aparecen en el fondo de la estructura, entremezclados con huesos de animales y materiales cerámicos y líticos (González, 1986: 82).

En cambio, la estructura $X$ - 1 está constituida por dos silos comunicados entre sí y de planta circular. Se desconoce si son silos germinados intencionados 
o se hundió la pared, que los separaba. Ambos contenían enterramientos. En el denominado $X-1$.A, (el silo más profundo) se registran dos niveles de enterramiento: un primer nivel con una gran concentración de huesos humanos sin ninguna conexión anatómica (entre los que se han localizado cuatro cráneos) y bajo esta y prácticamente sobre el suelo de la estructura, se depositó una inhumación colocado en decúbito lateral, con la cabeza apoyado sobre el miembro superior derecho, y el izquierdo sobre el tronco y los miembros inferiores ligeramente flexionados. Junto al cráneo apareció un recipiente cerámico completo. Por todo el silo, se observaban restos de fauna, (destacando sobre todo mandíbulas). Mientras que el silo X- I. B (el menos profundo) sólo se detectó un nivel de enterramiento, casi en la base. Por una parte un individuo con cierta conexión anatómica, pero incompleto; y aparte, aparece un amontonamiento de restos observándose huesos largos y un cráneo (González, 1986: 83).

Otra estructura, es la denominada LL, la cual es la más Ilamativa desde el punto de vista del ritual funerario. Es de forma abovedada y con unas dimensiones aproximadas de 2,10 m. de diámetro de base y $1 \mathrm{~m}$. de potencia. La boca, muestra indicios de haber estado sellada, por una gran acumulación de piedras en un lateral. En la base de la estructura fueron depositados tres individuos, en torno a las paredes del silo (a modo de círculo), estando dos de ellos en posición fetal y otro con los miembros inferiores ligeramente encogidas; mientras que en el centro se observa una importante acumulación de huesos de animales (suidos y ovicápridos). Esta deposición de los restos es una clara manifestación de intencionalidad. Junto a estos se encontraba una vasija cerámica entera, una piedra de molino barquiforme y algunos útiles líticos. (González, 1986: 84).

\section{Necrópolis Las Valderas (Arcos de la Frontera, Cádiz)}

\section{Ubicación}

Se localiza en la campiña de Arcos de la Frontera (Lazarich et al., 2001).

\section{Historia de la investigación}

Se localizó a comienzos de los años ochenta, debido a unas obras de ensache de una carretera, cuando la maquinaria sacó a la luz seis estructuras siliformes excavadas en la roca arenisca y de morfología acampanada. Su excavación estuvo a cargo de un equipo del Museo Provincial de Cádiz, los cuales solo pudieron documentar y recuperar los materiales que contenían dichos silos. Las estructuras de silos eran: I y II (germinados); mientras que los silos III, IV, VI, VII y VIII son estructuras aisladas aunque cercanas las unas a las otras. Estos últimos contenían diferentes materiales como: cerámica (restos amorfos acompañados de un machacador manchado de óxido de hierro y fragmentos de galbos cerámicos), junto 
con dos lascas, una lasca interna de sílex y una de semidescortezado en cuarcita (Lazarich et al., 2001: 86).

\section{Estructuras funerarias y ajuar}

En los silos (I y II) se localizaron restos de al menos tres individuos, junto a tres vasijas (una de ellas carenada) y un fragmento de plato que conserva un mamelón al que se le realizaron cuatro perforaciones (ajuar). En el filo de la estructura se documentaron una serie de materiales asociados a esta estructura como son: dos grandes azuelas de dolerita tallado y pulimentada y junto a ella un puñal o alabarda tallada en sílex y un objeto de hueso (probable empuñadura o parte del mango). También se hallaron dos hojas-cuchillo, tres puntas de flecha de base cóncava y aletas poco marcadas en sílex y un fragmento de lámina de cristal de roca. Más alejado a estas, (fuera del silo, en superficie) se encontraron una hoja-cuchillo que muestra en su extremo distal un raspador (Lazarich et al., 2001: 83). Por otro lado, en el silo VI se encontraron restos humanos pertenecientes, al menos a un individuo y junto a ellos se localizaron dos hojas cuchillo, un fragmento de hojita, un puñal de sílex, un plato completo, un pequeño vasito y varios fragmentos amorfos (Lazarich et al., 2001: 83).

\section{El Jadramil (Arcos de la Frontera, Cádiz)}

\section{Ubicación}

El yacimiento está ubicado a unos $5 \mathrm{~km}$. de la localidad de Arcos de la Frontera y cercano a la sierra de Gibalbin. El cerro de El Jadramil, está formado por areniscas calcáreas. La zona se caracteriza por ocupar pequeños cerros, con un buen control de visibilidad y una buena zona de aprovechamiento agrícola (Lazarich, 1999: 80).

\section{Historia de la investigación}

Se tiene noticas del asentamiento hacia primeros del siglo XX, haciendo referencia a unos túmulos que contenían restos humanos. Ya a mediados de los años ochenta debido a una serie de obras cercanas al yacimiento aparecieron una gran cantidad de material de diferentes cronologías: cerámicas e instrumentos líticos de sílex de época calcolítica y vasijas de época ibérica y romana. Debido a que la zona era utilizada como cantera de áridos en 1991, se realizó un control de superficie donde se localizaron diferentes estructuras siliformes (algunas con enterramientos). Debido a la continua explotación de la cantera, un año después, se continuaron con las excavaciones en tres zonas: I y II donde se localizaron diversas estructuras subterráneas calcolíticas; y en la zona III donde se localizó 
una necrópolis tardorromana con seis sepulturas. Finalmente, se reanudaron las actividades arqueológicas de urgencia hallándose diversas estructuras de la Edad del Cobre. En 1997, se llevó a cabo la última intervención de urgencia, poniendo al descubierto de nuevo enterramientos (ocho sepulturas de incineración) de los siglos I'-II ${ }^{\circ}$ d. C. (Lazarich et al., 1999: 82).

\section{Estructuras funerarias y ajuar}

Se localizan varias necrópolis: Prehistórica y Tardorromana. Debido a los parámetros del presente trabajo solo nos centraremos en la Prehistórica. Esta fue localizada durante la primera campaña (1991) al ser arrasadas por las máquinas de la cantera. Los investigadores, dudan sobre si fueron las únicas estructuras, ya que, gran parte del yacimiento había sido destruido. Por tanto de los silos I y II solo quedaban muy pocos restos óseos junto con dos azuelas pulimentadas, una hoja de cuchillo y tres microlitos geométricos; mientras que del segundo, se localizaron varios fragmentos de hueso y un ajuar formado por un microlito geométrico, una punta de flecha (fracturada), dos lascas internas, una lasca de descortezado y varios fragmentos de cerámica bruñida y sin decorar (Lazarich, 2003:141-143).

El único silo que pudo ser excavado en su totalidad fue el 3, en el que se observaron restos con una coloración rojiza (ocre) y donde se documentaron cuatro individuos: Un primer individuo colocado en el lado Noroeste y en cúbito supino y con un ajuar compuesto por hojas-cuchillos con retoques de uso, trapecios y hachas y azuelas pulimentadas y algunas vasijas globulares; un segundo individuo sin una clara conexión anatómica, junto con unas hojas-cuchillos de sílex y algunos fragmentos de cerámica. Tras ellos aparecía una capa de tierra cubriendo todo el espacio. El tercer individuo fue localizado en posición fetal y sin ningún ajuar en el lado opuesto a los anteriores. Y Finalmente se depositó un cuarto individuo, ligeramente a una altura superior que el resto, en el centro de la estructura junto a una azuela pulimentada y una hoja-cuchillo de sílex. Según sus investigadores, entre estos dos últimos individuos se encontraba una piedra de mediano tamaño, tal vez a modo de separación. Sin embargo, debido a que la zona había sido destruida por la maquinaria, no se descarta que tuviera otra distribución (Lazarich, 2003: 144).

\section{Consideraciones generales y conclusiones}

Como se ha podido documentar en líneas anteriores existe una gran cantidad de yacimientos prehistóricos con enterramientos en silo, los cuales en la gran mayoría de los casos, los restos óseos no habían sido estudiados. Por nuestra parte, como se ha citado en la introducción de este texto, este proceso se está desarrollando ahora mediante la elaboración de una tesis doctoral, ya que en- 
tendemos la necesidad del estudio de los huesos. Compartimos la idea que defendía D. Brothwell (1987): "El esqueleto humano representa una materia de investigación no menos fructífera que la cerámica, los metales, la arquitectura o cualquier otro campo de estudio, histórico o prehistórico.", y es que los huesos humanos no sólo aportan información biológica, sino que también son una fuente importante de información cultural, ya que se observa un fuerte paralelismo entre la posición social de un individuo en vida y el tratamiento que recibe, en el momento de su muerte, por parte del grupo (Castro et al., 1995).

El ritual funerario abarca desde el inicio de la construcción de la estructura de enterramiento hasta las ceremonias y el aporte de objetos que conformarán el ajuar, siendo en ocasiones, su adquisición un gran esfuerzo por parte de todo el grupo. Y por tanto los rituales serán diferentes para un individuo u otro, y reflejarán el tránsito de una sociedad tribal de grupos familiares a sociedades clasistas iniciales (Arteaga, 1992).

Las últimas investigaciones, indican que muchos enterramientos de animales constituyen un acto ritual e inaugural de un área. La aparición de restos humanos en estas mismas estructuras, demuestra un reaprovechamiento de las mismas, ya que, mediante la obtención de dataciones se ha observado que existe una diferencia temporal entre el enterramiento animal con el del hombre, por tanto, demuestran que existe una amplia diferencia temporal entre la construcción de una estructura y la utilización (Afonso et al., 2014:154). Tanto el ajuar, como los objetos depositados dentro de los diferentes enterramientos según su cronología, demuestran claramente que están en plena relación con la posición en vida del individuo y su tratamiento en el entierro. Esto se observa sobre todo, comparando con los objetos de prestigio y exóticos, depositados en las estructuras megalíticas; mientras que en el resto de los tipos de enterramientos, destaca un ajuar con material de uso cotidiano de esta comunidad (cerámica, herramientas líticas y elementos afines a su etapa cultural). Debido a su proximidad al mar, se destaca en su mayoría la presencia de malacofauna. Es necesario realizar un análisis exhaustivo de los diferentes poblados con el fin de corroborar o no la existencia de las desigualdades sociales que muestran posteriormente las estructuras (Vicent, 1995). Estas grandes diferencias, se verán sobre todo con la aparición del fenómeno del megalitismo, ya que son estructuras construidas por una gran parte de la población, pero no todos tenía el privilegio de ser enterrados en ellas.

Los enterramientos en silo son las estructuras de inhumación de época prehistórica que más problemática y más discusión han generado entre la comunidad científica. Se acepta las hipótesis que sugieren que en ellos se enterraban la gran parte de la población, mientras que un grupo minoritario de rango superior, se enterraban en sepulcros de mayor monumentalidad (Nocete, 2001). La reutilización de estructuras creadas para otro fin, en este caso, para almacenaje de alimentos y la ausencia de ajuares significativos junto con los restos óseos. Aun- 
que existen en estos yacimientos dos vertientes: por una parte los enterramientos claramente intencionados y con un ritual claro; mientras que en otros, en el mismo yacimiento, se documentan silos que albergan restos óseos, fauna y cerámica y/o industria lítica (Márquez y Jiménez, 2010:233).

Esto se puede observar claramente en el yacimiento de El Trobal (Jerez de la Frontera), donde se observan dos silos: X-1 y LL con un claro ritual e intencionalidad a diferencia de los otros dos Z-1 y B, donde no hay una cuidada colocación de los restos óseos humanos con los otros materiales que aparecen. También se observa en el yacimiento de La Esparragosa (Chiclana de la Frontera) donde un solo individuo fue cubierto con almejas (muchas de ellas cerradas), mostrando una clara ritualización por parte del grupo ante el difunto.

Por otro lado están los yacimientos donde los restos óseos no muestran un clara ritualización a diferencia de los yacimientos anteriormente citados, como es el caso de SET Parralejos cercano a Vejer de la Frontera, Las Viñas-Cantarranas y Base Naval de Rota, todas ellas cercanas a la población del Puerto de Santa María.

Todos los yacimientos con silos, tienen unas cronologías similares, sobre todo en torno al tránsito $\mathrm{IV}^{\mathrm{O}}$ - III ${ }^{\mathrm{O}}$ milenio a.n.e y mediados del III ${ }^{\mathrm{O}}$ milenio a.n.e. Esto viene corroborado por la similitud con otros yacimientos cercanos y similares como es "El Trobal" en Jerez de la Frontera, "Las Viñas- Cantarranas" o "Base Naval de Rota" en el Puerto de Santa María, "La Esparragosa" en Chiclana de la Frontera, o SET Parralejos en Vejer de la Frontera u otros como «Papa Uvas» (Aljaraque, Huelva) (final de Fase II y Fase III) o "Los Castillejos» (Montefrío, Granada) (Fase II e inicios de Fase III) (González, 1986:88). Todos estos yacimientos se han visto corroborados por dataciones que se han realizado a posteriori de las excavaciones arqueológicas y confirmando las fechas iniciales a través de las tipologías de las estructuras o del ajuar.

Estos yacimientos con silos y con enterramientos en estas estructuras, están presentes en muchas zonas europeas de la Prehistoria Reciente, generando una literatura científica procedente de los ámbitos académicos y científicos.

Respecto a las investigaciones sobre las estructuras de enterramiento no está todo escrito y es necesaria una fuerte carga de inversión en excavaciones arqueológicas y análisis en profundidad con equipos multidisciplinares. En casi todos los yacimientos presentados, ha faltado la realización de los estudios antropológicos, los cuales no solo aportarían una rica información biológica, sino también cultural, aportando una gran información sobre qué individuos se entierran en diferentes estructuras y qué características biológicas tenían (sexo, edad, patologías, entre otros marcadores que pueden aportar una rica información a las investigaciones). Las nuevas investigaciones y métodos lograrán el solventar estos "vacíos" de investigación, referidos a este campo y completar más aun las investigaciones sobre las poblaciones prehistóricas. 


\section{Bibliografía}

AFONSO MARRERO, J. A.; CÁMARA SERRANO, J. A.; SPANEDDA, L.; ESQUIVEL GUERRERO, J. A.; LIZCANO PRESTEL, R.; PÉREZ BAREAS, C.; RIQUELME CANTAL, J. A. (2014): "Nuevas aportaciones para a periodización del yacimiento del Polideportivo de Martos (Jaén): la evaluación estadística de las dataciones obtenidas para contextos rituales" Archivo de Prehistoria Levantina. Vol. XX, pp. 133-158. Valencia.

ARTEAGA, Oswaldo. (1992): "Tribalización, jerarquización y estado en el territorio de El Algar". Spal,1. Universidad de Sevilla. pp. 179 -2008.

BROTHWELL, Don. (1987): Desenterrando huesos. Fondo de Cultura Económica. México.

CÁMARA SERRANO, J. A.; RIQUERME CANTAL, J. A.; PÉREZ BAREAS, C.; LIZCANO PRESTEL, R.; BURGOS JUÁREZ, A.; TORRES TORRES, F. (2010): "Sacrificio de animales y rituales en el polideportivo de Martos-La Alberquilla (Martos, Jaén)". Cuadernos de prehistoria y arqueología de la Universidad de Granada, № 20, (Ejemplar dedicado a: Aplicaciones informáticas en arqueología), pp. 295-327. Granada.

CÁMARA SERRANO, J. A. (2001): El ritual funerario en la Prehistoria Reciente en el Sur de la Península Ibérica. British Archaeological Reports. International Series 913, Oxford.

CASTRO MARTíNEZ, P.; LULL SANTIAGO, V.; MICÓ PÉREZ, R.; RIHUETE HERREDA, C. (1995): "La prehistoria reciente en el sudeste de la península ibérica. Dimensión socio-económica de las prácticas funerarias", en R. FÁBREGAS, F. PÉREZ y C. FERNÁNDEZ (eds.): Arqueoloxía da Morte na Península Ibérica desde as Orixes ata o Medievo. Biblioteca Arqueohistórica Limiá, Serie Cursos e Congresos 3, Xinzo de Limia, pp 127-167.

CORZO SÁNCHEZ, R. (1983): “Necrópolis de la Edad del Bronce en Las Valderas (Arcos)". Arqueologia 83:12. Ministerio de Cultura. Madrid.

CUENCA SOLANA, D.; CANTILLO DUARTE, J. J.s; VIJANDE VILA, E.; MONTAÑÉS CABALLERO, M.; CLEMENTEN CONDE, I.; VILLALPANDO MORENO, A. (2013): "Utilización de instrumentos de concha para la realización de actividades productivas en sociedades tribales comunitarias del Sur de la Península Ibérica. El ejemplo de Campo de Hockey (San Fernando, Cádiz) y SET Parralejos (Vejer de la Frontera, Cádiz)." Zephyrus, LXXII, julio-diciembre 2013, pp. 95-111. Universidad de Salamanca.

GONZÁLEZ RODRíGUEZ, R. (1986): "El yacimiento de "El Trobal" (Jerez de la Frontera, Cádiz). Nuevas aportaciones a la cultura de los silos de la Baja Andalucía". Anuario Arqueológico de Andalucía III. Actividades de Urgencia, pp. 82-88. Sevilla. 
LAZARICH GONZÁLEZ, M. (2003): El Jadramil (Arcos de la Frontera). Estudio arqueológico de un asentamiento agrícola en la campiña gaditana. Ayuntamiento de Arcos de la Frontera.

LAZARICH GONZÁLEZ, M.; BUENO SÁNCHEZ, O.; RICHARTE GARCÍA, Mª. (2001): "Estudio antropológico y de los productos arqueológicos hallados en la Necrópolis de "Las Valderas" (Arcos de la Frontera, Cádiz), depositados en los fondos del Museo Provincial de Cádiz.". Anuario Arqueológico de Andalucía, II. Actividades sistemáticas y puntuales. pp. 83 - 91.Junta de Andalucía. Sevilla.

LIZCANO PRESETEL, R.; CÁMARA SERRANO, J. A. (2004): "Producción económica y sedentarización. El registro arqueológico del Polideportivo de Martos (Jaén)", Sociedades recolectoras y primeros productores. Actas de las Jornadas Temáticas Andaluzas de Arqueología (Ronda, 28-30 de octubre de 2003), Consejería de Cultura, Junta de Andalucía, Sevilla, pp. 229-248.

MORENO MÁRQUEZ, A. (2015): "Yacimientos con estructuras funerarias de la prehistoria reciente en la Campiña Litoral y Banda Atlántica de Cádiz. Estado de la Cuestión". Revista Atlántica- Mediterránea de Prehistoria y Arqueología Social, 17, pp. 113-120. Servicio de Publicaciones de la Universidad de Cádiz.

MÁRQUEZ ROMERO, J. E.; JIMÉNEZ JÁIMEZ, V. (2010): Recintos de fosos: Genealogía y significado de una tradición en la Prehistoria del suroeste de la Península Ibérica (IV-III milenios AC). Servicio de Publicaciones y Divulgación Científica de la UMA

NOCETE CALVO, F. (2001): Tercer Milenio antes de Nuestra Era. Relaciones y contradicciones centro/ periferia en el Valle del Guadalquivir. Bellaterra. Barcelona. PÉREZ RODRÍGUEZ, M.; RAMOS MUÑOZ, J.; VIJANDE VILA, E.; CASTAÑEDA FERNÁNDEZ, V. (2005): "Informe preliminar de la excavación arqueológica de urgencia en el asentamiento prehistórico de La Esparragosa (Chiclana de la Frontera)". Anuario Arqueológico de Andalucía, 2002, III, pp. 93-103. Junta de Andalucía.

RAMOS MUÑOZ, J.; CANTALEJO DUARTE, P. (2015): “Las sociedades prehistóricas en el entorno del actual término de Casabermeja" pp. 36-72 en MARTíNEZ ENAMORADO, V. (dir.), LÓPEZ GARCÍA, E., FERNÁNDEZ MARTÍN, A. (coords.) Casabermeja, un lugar para la historia. Volumen I.

RAMOS MUÑOZ, J. (coord.) (2008): La ocupación prehistórica de la campiña litoral y Banda Atlántica de Cádiz. Aproximación al estudio de las sociedades cazadoras- recolectoras, tribales-comunitarias y clasistas iniciales, Arqueología Monografías. Sevilla: Consejería de Cultura de la Junta de Andalucía.

RUIZ FERNÁNDEZ, J. Á.; RUIZ GIL, J. A. (1989): "Calcolítico en el Puerto de Santa María". Revista de Arqueología 94, pp. 7-13. Madrid.

RUIZ GIL, J.A.; RUIZ FERNÁNDEZ, J.A. (1987): "Excavaciones de urgencia en el Puerto de Santa María, Cádiz". Revista de Arqueología, n. 74, pp. 5-12. Madrid. 
RUIZ GIL, J. A. (1986): "Informe excavaciones de urgencia. Pago de Cantarranas La Viña. El Puerto de Santa María". Anuario Arqueológico de Andalucía, III, Actividades de Urgencia, pp. 95-110. Junta de Andalucía. Sevilla.

VALVERDE LASANTA, M. (1993): El taller de Cantarranas (El Puerto de Santa María, Cádiz. Un ejemplo para la transición Neolítico-Calcolítico. Servicio de Publicaciones. Universidad de Cádiz.

VICENT GARCíA, J. M. (1995): "Problemas teóricos de la Arqueología de la Muerte Una introducción". En R. FÁBREGAS, F. PÉREZ y C, Fernández (eds.): Arqueoloxía da Morte na Península Ibérica desde as Orixes ata o Medievo, pp.13-31. Excmo. Concello de Xinzo de Limia, Vigo.

VILLALPANDO MORENO, A.; MONTAÑÉS CABALLERO, M. (2009): "Avance de resultados de las excavaciones arqueológicas realizadas en la SET Parralejos". Revista Atlántica- Mediterránea de Prehistoria y Arqueología Social, 11, pp. 257-264. Servicio de Publicaciones de la Universidad de Cádiz.

VIJANDE, E. (2006): Prehistoria reciente de Chiclana de la Frontera. Aportación al conocimiento de las formaciones sociales tribales y clasistas iniciales en el marco de la banda atlántica gaditana. Universidad de Cádiz. Servicio de Publicaciones. 
